\title{
Illuminating Southeast Asian Prehistory: New Archaeological and Paleoanthropological Frontiers for Luminescence Dating
}

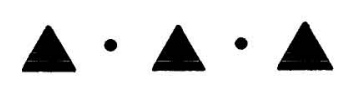

\author{
RICHARD G. ROBERTS, M. J. MORWOOD, AND \\ KIRA E. WESTAWAY
}

ROBUST CHRONOLOGIES FOR THE EXTINCTION of Homo erectus, the arrival of modern humans (Homo sapiens), and the dispersal of Neolithic peoples throughout Southeast Asia and Oceania are needed to assess general models of human evolution and dispersal worldwide. At present, the lack of adequate age control has created a deadlock between proponents of the "multiregional" hypothesis of modern human evolution, who argue that modern humans arose by evolutionary changes in earlier hominid populations in many parts of the Old World, and advocates of the "out of Africa" hypothesis, who hold the view that modern humans first appeared in Africa less than 200,000 years ago and then dispersed across the world, eclipsing all earlier hominid populations (Bräuer and Smith 1992; Storm 2001; Stringer 2002, 2003; Templeton 2002). Reliable ages for the critical Homo erectus and early modern human sites in Southeast Asia (Figure 1) are needed to discriminate between these two models and their variants. The recent discovery of a new species of hominin (Homo floresiensis) from late Pleistocene deposits on the island of Flores in eastern Indonesia (Brown et al. 2004; Morwood et al. 2004) further highlights the key role of Southeast Asia in the story of human evolution - a tradition begun more than a century ago by Eugène Dubois (Shipman 2001).

From a regional perspective, the present lack of a robust chronology for the major turning points in the Southeast Asian cultural and evolutionary sequences makes it futile to speculate on whether Homo erectus, Homo sapiens, and Homo floresiensis ever came into contact; what form any contact may have taken; what impact archaic and modern humans may have had on the landscape, fauna, and flora; and what effect major environmental changes (e.g., volcanic eruptions, such as the Toba explosion about 74,000 years ago) may have exerted on the resident

Richard G. Roberts, Professor and ARC Senior Research Fellow, GeoQuEST Research Centre, School of Earth and Environmental Sciences, University of Wollongong. M. J. Morwood, Professor, Archaeology and Paleoanthropology, School of Human and Environmental Studies, University of New England. Kira E. Westaway, Doctor of Philosophy Candidate, GeoQuEST Research Centre, School of Earth and Environmental Sciences, University of Wollongong. 


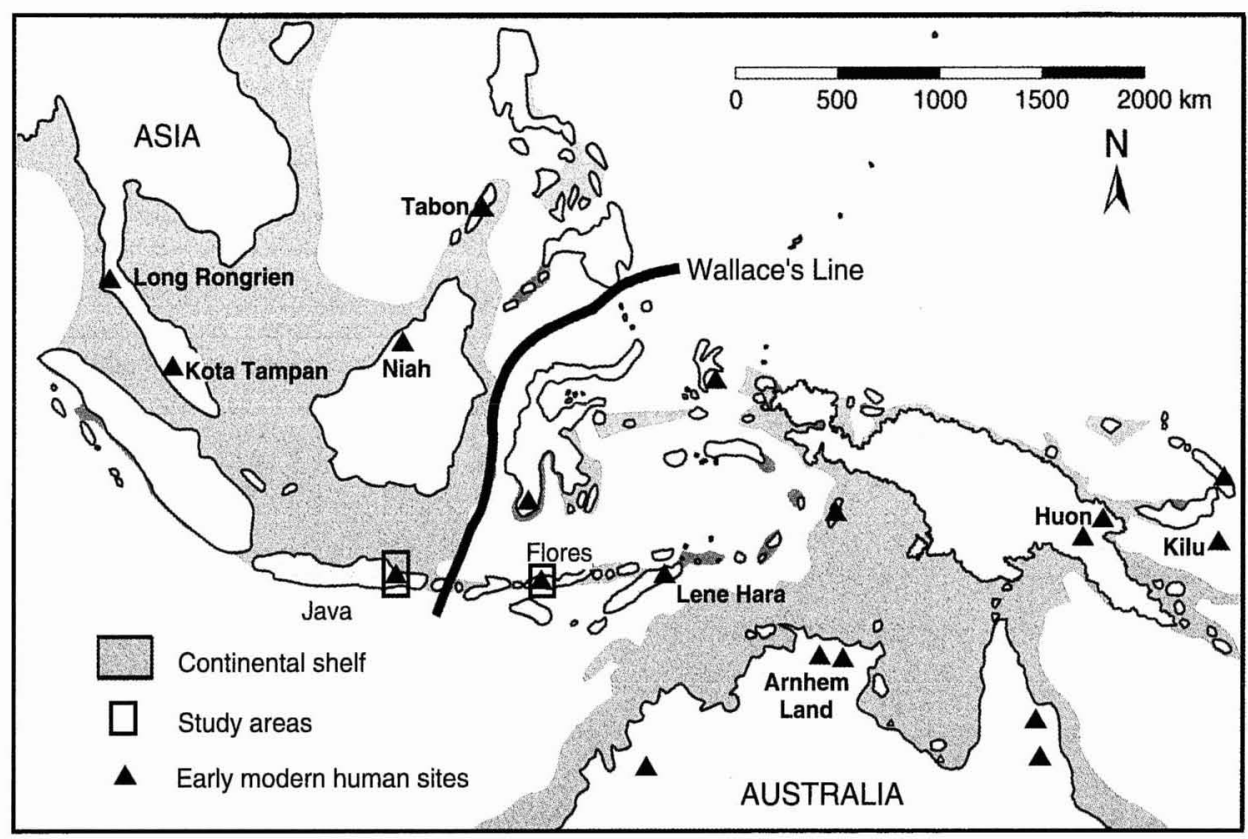

Fig. 1. Map of Southeast Asia showing the position of Wallace's Line-the most significant biogeographical boundary in the region-and the locations of some sites associated with the first appearance of modern humans. Our research will focus initially on two study areas, which lie on either side of Wallace's Line: the Solo River Basin (and neighboring region) in Java, and the Ruteng area of western Flores.

human populations through modifications to the climate and habitat (Ambrose 1998; Oppenheimer 2002).

The reasons for these chronological conundrums are multifarious and often complex. For example, Swisher et al. (1994) reported ${ }^{40} \mathrm{Ar} /{ }^{39} \mathrm{Ar}$ ages of 1.61.8 million years for hornblende crystals collected from volcanic units thought to be directly associated with early hominid remains at Sangiran and Mojokerto in central and eastern Java. While accurate and precise ages for mineral crystallization may be determined by ${ }^{40} \mathrm{Ar} /{ }^{39} \mathrm{Ar}$ dating (and the allied technique of potassium-argon, $\mathrm{K}-\mathrm{Ar}$ ), the extension of these ages to finds of archaeological and paleoanthropological interest requires that two criteria be satisfied. The first is that the dated minerals must be in direct association with the artifacts or fossils. Such an association is not straightforward to demonstrate in the case of the early Javan fossils, because they were collected many years before the ${ }^{40} \mathrm{Ar} /{ }^{39} \mathrm{Ar}$ samples-more than half a century earlier in the case of the Mojokerto calvaria-and Swisher et al. (1994) were unable to obtain sufficient hornblende from the Mojokerto calvaria for ${ }^{40} \mathrm{Ar} /{ }^{39} \mathrm{Ar}$ dating. Consequently, uncertainties persist about the exact stratigraphic relation of the fossils to the dated hornblende crystals (de Vos and Sondaar 1994).

The second criterion is that, even when direct association is demonstrated, the dated minerals should be in primary depositional context. There otherwise re- 
mains the possibility that the crystals were eroded from an older deposit and then, still bearing their original crystallization age, were incorporated with artifacts and fossils in younger deposits; de Vos and Sondaar (1994) argued that this was likely to be the case at Mojokerto. $\mathrm{K}-\mathrm{Ar}$ and ${ }^{40} \mathrm{Ar} /{ }^{39} \mathrm{Ar}$ dating should, therefore, be restricted to in situ volcanic deposits (Clark et al. 2003; Larick et al. 2001) and with extreme circumspection applied to fluvial deposits, as rivers commonly entrain crystals derived from rocks and sediments of diverse ages.

At the recent end of the Pleistocene timescale, Swisher et al. (1996) reported equally controversial ages of 27,000-53,000 years for Homo erectus remains recovered from river terrace and channel deposits at Ngandong, Jigar, and Sambungmacan in central Java. These classic Homo erectus sites are clustered along a $60-\mathrm{km}$ reach of the Solo River, where the river terraces have yielded what are generally regarded as the most recent examples of the species. Along the same reach of river lies the site of Trinil, where Eugène Dubois discovered the type specimen of Homo erectus in the late nineteenth century. The Homo erectus fossils from Trinil and Sangiran-located farther upstream-are generally considered (Bellwood 1997; Larick et al. 2001) to be much older than the remains found at Ngandong and Sambungmacan, but accurate ages for the latter have remained elusive.

A major problem in determining the ages of the most recent Homo erectus remains, which are represented mostly by crania, has been the lack of any reliable means of direct dating. The claims for Homo erectus survival until as recently as 27,000 years ago (Swisher et al. 1996) were based on electron spin resonance (ESR) and uranium-series (U-series) dating of fossil animal (bovid) teeth buried alongside Homo erectus remains. Hence, it is necessary to satisfy the first criterion discussed above in regard to the early Javan hominids: direct association of the Homo erectus remains and the dated material (bovid teeth, in this instance). The lack of any articulated remains suggests that the hominid fossils were reworked from elsewhere, possibly from fluvial deposits much older than either the final burial sediments or the bovid teeth. Consequently, the assumption that the hominid fossils are contemporaneous with the bovid teeth has been challenged on the grounds that rivers commonly transport reworked sediments and fossils of mixed ages and that the human and faunal remains differ in their state of preservation (Gibbons 1996; Grün and Thorne 1997; Westaway 2002). At present, therefore, no consensus has been reached on the age of the Ngandong and Sambungmacan hominids, other than a broad constraint to the late or middle Pleistocene (Antón 2002; Baba et al. 2003; Bartstra et al. 1988; Jacob et al. 1978; Sartono 1980; Swisher et al. 1996; Theunissen et al. 1990).

In addition to the various question marks hanging over the dates of arrival and extinction of Homo erectus in Indonesia, there are lingering concerns as to when Homo sapiens first entered Southeast Asia and made landfall in Australia (O'Connell and Allen 2004). Luminescence dating of two archaeological sites in the Arnhem Land region of northern Australia (Figure 1) suggests that modern humans colonized the continent between 50,000 and 60,000 years ago (Roberts and Jones 2001; Roberts et al. 1990; Roberts et al. 1994). Such ages lie beyond the practical limit for radiocarbon $\left({ }^{14} \mathrm{C}\right)$ dating of charcoal when conventional sample preparation procedures are employed. But preparation of charcoal samples using the new 
acid-base wet oxidation and stepped-combustion (ABOX-SC) technique permits ${ }^{14} \mathrm{C}$ dating back to 55,000 years (Bird et al. 1999). At some Australian sites, this has increased the apparent ${ }^{14} \mathrm{C}$ ages of charcoal samples older than about 20,000 years by 10,000 years or more and demonstrated that the previous date of 40,000 years for initial human colonization is a laboratory artifact (Smith et al. 2001; Turney et al. 2001). Because the first people to reach Australia had to pass through Southeast Asia, we might expect, therefore, that modern human populations had colonized the region by 50,000-60,000 years ago.

Several key sites documenting the arrival of modern humans in Indonesia, Thailand, Malaysia, and the Philippines have been dated by ${ }^{14} \mathrm{C}$, yielding age estimates of 30,000 years or more for initial occupation: for example, Lang Rongrien in southern Thailand (Anderson 1987), Tabon Cave in the Philippines (Pawlik 2001), and Niah Cave in Sarawak (Barker et al. 2001) (Figure 1). Ages of this order are uncomfortably close to the practical limit of ${ }^{14} \mathrm{C}$ dating when samples are prepared using conventional procedures. ABOX-SC preparation methods were employed only at Niah Cave, where modern human skeletal remains are at least 42,000 years old (Barker et al. 2001), so the true ages of other early Homo sapiens sites in Southeast Asia need to be reassessed in light of the Australian evidence. ABOX-SC ${ }^{14} \mathrm{C}$ dating may yield reliable ages for deposits containing charcoal fragments less than 55,000 years old, but alteration of charcoal in tropical environments can give rise to substantial age underestimates (Bird et al. 2002). The most prudent course of action, therefore, is to date sites using a variety of techniques that are founded on different physical principles, to avoid any chronological distortion arising from inadequacies of any particular method.

Given the lack of reliable age constraints on the earliest hominids and latest Homo erectus remains in Java, and-with the notable exception of Niah Cavethe earliest evidence for modern humans throughout Southeast Asia, there is a clear need for new and improved dating strategies. The application of luminescence dating methods - a family of radiation dosimetry techniques that includes thermoluminescence (TL) and optical dating-presents a novel opportunity to meet this need. Luminescence methods have been applied to many archaeological sites around the world (Feathers 1997, 2003; Roberts 1997), but to few in Southeast Asia. TL and optical dating operate on fundamentally different principles than most other dating techniques (yielding estimates of the time elapsed since minerals were last exposed to heat or sunlight) and are not subject, therefore, to the same methodological problems and limitations. They can typically be applied to sediments deposited in the last few hundreds of thousands of years - the time period of critical importance to a number of major turning points in the cultural and evolutionary sequences of Southeast Asia, including the disappearance of Homo erectus and Homo floresiensis, and the arrival and dispersal of Homo sapiens in the region.

We describe below some of the key archaeological and paleoanthropological questions being pursued in our current program of luminescence dating in Southeast Asia, and present some of our initial results for sites in Indonesia (Liang Bua) and Malaysia (Bukit Bunuh). We shall begin, however, with a brief account of the history and physical basis of luminescence dating, making specific reference to archaeological applications and the challenges posed by minerals of volcanic origin, which are ubiquitous in Indonesian deposits. 


\section{LUMINESCENCE DATING IN ARCHAEOLOGY}

Half a century has elapsed since the American chemist Farrington Daniels and his colleagues first proposed that luminescence dating methods could play a valuable role in archaeological research (Daniels et al. 1953). At that time, they foreshadowed that "the possibility of estimating the dates at which limestones and ancient pottery were heated to high temperatures is now being explored" (Daniels et al. 1953:349) - a reference to the technique of TL dating, in which the light emitted when materials are heated in the laboratory to a high temperature (about $500^{\circ} \mathrm{C}$ ) is measured using a photomultiplier tube (which can detect emissions that are too faint to be seen by the naked eye).

The next two decades of luminescence research were dominated by developments in TL dating, and especially their application to ancient pottery that had been fired at the time of manufacture. Laboratories in England (Aitken et al. 1964; Aitken et al. 1968), Denmark (Mejdahl 1969), Japan (Ichikawa 1965), and the United States (Mazess and Zimmerman 1966; Ralph and Han 1966) led the way with the analysis of pottery from Europe, Asia, and South America. Many samples proved suitable for the TL technique, using the silt-size grains (Zimmerman 1971) or sand-size quartz inclusions (Fleming 1970) embedded in the matrix, but TL dating first broke new ground in archaeological research when Zimmerman and Huxtable (1971) applied the technique to burnt clay lumps from the Upper Paleolithic site of Dolní Věstonice. This was the first time that TL dating had been extended into the Paleolithic - a period that lies mostly beyond the limits of ${ }^{14} \mathrm{C}$ dating and for which luminescence chronologies have since made significant contributions to world archaeology and paleoanthropology.

Further developments in TL dating followed quickly, beginning with the age determination of burnt flints (Göksu et al. 1974). This technique was subsequently refined and applied to Neanderthal and early modern human sites in western Europe and the eastern Mediterranean, overturning conventional wisdom about modern human evolution (Mercier et al. 1995; Valladas et al. 1987; Valladas et al. 1988). But TL methods filled the archaeological dating vacuum only when it was realized that they could also be used to date sediments that had never been burnt but had been exposed to sunlight immediately prior to deposition (Singhvi et al. 1982; Wintle and Huntley 1979, 1982). Suddenly the antiquity of whole landscapes, cultural as well as natural, was an issue that could be addressed by TL dating of sun-bleached sediments, and dating of cultural sediments resurrected the possibility of obtaining ages for artifacts and human remains at archaeological sites where burnt flints or pottery were absent.

The application of TL dating techniques to archaeological sediments has had its greatest impact in Australia (Roberts et al. 1990), Africa (Brooks et al. 1995), and eastern Asia (Waters et al. 1997). A major step forward to improving the reliability of luminescence age estimates was made with the development of optical dating techniques for quartz (Huntley et al. 1985) and potassium feldspar (Hütt et al. 1988), two of the most commonly occurring minerals on Earth. Zircons are another potential candidate for TL and optical dating, but technical difficulties have frustrated their routine use (Aitken 1998; van Es et al. 2002).

Optical and TL dating are closely related techniques, but optical dating exploits the light-sensitive, rather than heat-sensitive, signals. The photon-stimulated 
luminescence (PSL) signals - known also by the terms "optically stimulated luminescence" (OSL) for quartz and "infrared-stimulated luminescence" (IRSL) for feldspar-are set to zero (or nearly so) by just a few seconds of exposure to sunlight, in contrast to the several hours of exposure required to reset the TL signal. For this reason, optical dating is now the generally preferred means of dating sunbleached sediments, and it has received widespread archaeological application in Australia (Roberts et al. 1994; Roberts et al. 1998), Africa (Feathers and Bush 2000; Henshilwood et al. 2002), and Europe (Lang and Wagner 1996; ReesJones and Tite 1997). Recent reviews of luminescence dating methodology and archaeological applications include Aitken and Valladas (1992); Mercier et al. (1995); Aitken (1997); Feathers (1997, 2003); Roberts (1997); and Troja and Roberts (2000). Additional technical details may be found in Aitken (1985, 1998), Wintle (1997), Lian and Huntley (2001), and Bøtter-Jensen et al. (2003).

As regards archaeological applications in Southeast Asia, TL and optical dating have been largely restricted to manmade objects and features, such as fired pottery from Thailand (Zimmerman and Huxtable 1969) and sedimentary infills from canals in Cambodia (Sanderson et al. 2003). At the time of this writing, the only published luminescence ages relating to the Pleistocene prehistory of the region are those for Bukit Bunuh in Malaysia (Zuraina 2003:136) and Liang Bua in Indonesia (Morwood et al. 2004). Here we provide further discussion of those important samples, together with the supporting luminescence data.

\section{THE PHYSICS OF LUMINESCENCE DATING}

In idealized crystalline semiconductors and insulators, the structure of the crystal lattice does not permit electronic charge (that is, negatively charged electrons or positively charged "holes") to be trapped between the valence and conduction bands - the "forbidden energy gap". Absorption of energy from ionizing radiation (that is, radiation sufficient to create electrically charged atoms) results in electrons moving directly from the valence band to the conduction band. But natural minerals possess many lattice defects (e.g., chemical impurities, ionic vacancies, and interstitials), resulting in a gap between the valence and conduction bands where electrons and holes can be trapped at localized energy levels. In general, the deeper the electron trap below the conduction band, the greater the lifetime of the trapped electron. Some traps retain electrons for millions of years at the temperatures typical of the near-surface environment, and these are the traps exploited in luminescence dating.

Heating the minerals to above $250^{\circ} \mathrm{C}$ (as in $\mathrm{TL}$ dating) or exposing them to photons of suitable energy (as in optical dating) will empty the deep traps, and some proportion of the evicted electrons will recombine with trapped holes at "luminescence centers" (that is, defects with particular impurities). Light is emitted during this process and the color of the light is characteristic of the impurity. Glass filters are used in the laboratory to select particular emissions for dating. For both quartz and potassium feldspar, the blue/violet/ultraviolet region of the electromagnetic spectrum is conventionally chosen for TL and optical dating; this has permitted ages to be obtained back to 500,000 years with good reliability and to 
800,000 years with much less confidence (Berger et al. 1992; Huntley et al. 1993a, 1993b; Prescott et al. 2001; Yoshida et al. 2000).

A feature of some feldspars, however, is that significant leakage of electrons commonly occurs from deep traps at ambient temperature, resulting in "anomalous fading" (Wintle 1973) of the TL and IRSL signals. This can cause substantial age shortfalls unless corrections are made (Huntley and Lamothe 2001; Lamothe and Auclair 1999; Lamothe et al. 2003). Whether or not all feldspars suffer from fading is a moot point. For example, Lian and Shane (2000) could not discern any fading in their New Zealand samples over a storage period of 75 days, and, based on a comparison of optical ages with independent age control, they concluded that any age underestimation due to fading over longer timescales was insignificant. It is generally accepted that quartz does not fade (Aitken 1998).

The red emissions from quartz and feldspar have been largely avoided in TL dating because of the overwhelming red-hot glow from incandescence. But recent studies (Stokes and Fattahi 2003; Visocekas and Zink 1999) have found that the red TL and IRSL signals in potassium feldspars appear to be immune (or nearly so) from the deleterious effects of anomalous fading, making them attractive options for TL and optical dating of heated and sun-bleached sediments. The discovery of a light-sensitive red TL component in quartz also offers the prospect of dating unheated sediments using the red emissions (Franklin et al. 2000; Morwood et al. 2004; Scholefield and Prescott 1999), and the high dose-response characteristics of the red TL signal in quartz (Fattahi and Stokes 2003; Hashimoto et al. 1987; Miallier et al. 1991) opens up the possibility of dating beyond one million years-Fattahi and Stokes (2000) reporting a red TL age of 1.3 million years for volcanic quartz in New Zealand.

It may also be feasible to estimate the burial ages of quartz sediments deposited up to 5 million years ago from their light-sensitive ESR signals (Falguères 2003; Rink 1997) and from the in situ production of the cosmogenic nuclides ${ }^{26} \mathrm{Al}$ and ${ }^{10} \mathrm{Be}$ (Granger and Muzikar 2001; Partridge et al. 2003). But both of these techniques, and also luminescence dating using the red emissions, require further research to increase confidence in their age estimates, so dating cross-checks should be made whenever possible.

For both quartz and feldspar, similar TL and optical dating procedures are used to estimate the time elapsed since the silt-size or sand-size grains were last exposed to heat (e.g., when a pot was fired in antiquity) or to sunlight (e.g., during the most recent episode of sediment transport). Similar procedures are also adopted for TL dating of burnt flint and quartzite artifacts, but such materials are rarely encountered at archaeological or paleoanthropological sites in Southeast Asia. Once a pottery fragment or sediment is buried (that is, hidden from sunlight), the number of trapped electrons and holes increases steadily with time due to the background flux of ionizing radiation (the "dose rate") from the nuclear decay of the naturally occurring radioactive elements ${ }^{238} \mathrm{U},{ }^{235} \mathrm{U},{ }^{232} \mathrm{Th}$ (and their progeny), ${ }^{87} \mathrm{Rb}$, and ${ }^{40} \mathrm{~K}$, which are present inside sand-size grains of quartz and feldspar, in the clay matrix of pottery, and in the deposits that surround the sample to a distance of about $30 \mathrm{~cm}$. Cosmic rays, which continually bombard Earth, also contribute to the dose rate. It is necessary to estimate the time-averaged radioactivity and water content for the entire period of sample burial. Measure- 
ments of present-day radioactivity can be made at the site (e.g., using a portable gamma-ray spectrometer or TL dosimetry capsules) and in the laboratory (e.g., by $\mathrm{X}$-ray fluorescence spectrometry and neutron activation analyses of collected samples). But to identify and correct for the migration of radioactive elements in the past requires the use of high-resolution gamma-ray and alpha-particle spectrometry facilities (Aitken 1985; Krbetschek et al. 1994; Olley et al. 1997).

The trapped electrons are released, with an accompanying emission of light, when the sample is heated (TL dating) or illuminated (optical dating) in the laboratory. A green laser or blue light-emitting diodes are most commonly used to optically stimulate quartz, while feldspars can be conveniently stimulated using infrared-emitting diodes (Aitken 1998). The quantity of light emanating from the sample is used to determine the paleodose (also called the "equivalent dose"), which is the amount of radiation energy absorbed by the sample and stored as trapped electrons during the period of burial. The paleodose is expressed in grays (the SI unit for absorbed dose of ionizing radiation, where 1 gray $(\mathrm{Gy})=1 \mathrm{~J} / \mathrm{kg}$ ) and the TL or optical age is calculated from the following equation:

$$
\text { age }(\text { years })=\text { paleodose }(\mathrm{Gy}) / \text { dose rate }(\mathrm{Gy} / \text { year })
$$

Several different protocols are currently used to estimate the paleodose, the most suitable protocol depending on the particular mineral being dated, the luminescence characteristics of the sample, its age, and the process by which it was deposited (e.g., water-lain or wind-blown). A robust and increasingly popular protocol for optical dating of quartz (and, to a lesser extent, feldspar) from sediments and pottery is the single-aliquot regenerative-dose protocol (Aitken 1998; BøtterJensen et al. 2003; Murray and Wintle 2000; Roberts et al. 1998). This requires only a small amount of sample and facilitates the detection of insufficient bleaching or heating of the sample before the most recent burial event. It is usually possible to obtain reliable paleodoses using subsamples ("aliquots") that weigh only a few milligrams. Australian sedimentary quartz commonly emits a strong OSL signal and individual aliquots may consist of as few as 10-100 grains (Roberts et al. 2001; Turney et al. 2001), whereas aliquots composed of several hundred grains may be required in other instances. The OSL signals from New Zealand quartz, for example, are comparatively weak (Holdaway et al. 2002).

In certain circumstances, it may be necessary to date individual grains of sand, due to small sample size (Roberts et al. 1997), post-depositional mixing of older and younger strata (Roberts et al. 1998), or insufficient exposure to sunlight before deposition (Lamothe et al. 1994; Olley et al. 1999). The latter is the greatest potential cause of concern for luminescence dating of unheated sediments, especially young fluvial sediments (Olley et al. 2004). Even wind-blown silts, however, may be subject to incomplete bleaching if they are transported over short distances as grain aggregates (Lian and Huntley 1999). Insufficient bleaching can result in considerable age overestimates but, in most depositional environments, the optical dating signals of at least some of the quartz and feldspar grains are bleached sufficiently to yield reliable burial ages (Murray and Olley 2002; Olley et al. 2004). The latter ages reflect the time elapsed since the most recent sediment transportation and deposition event and, unlike ${ }^{40} \mathrm{Ar} /{ }^{39} \mathrm{Ar}$ or ${ }^{14} \mathrm{C}$ dating of reworked materials, there is no "inherited age" component to take into consideration. 


\section{ILLUMINATING SOUTHEAST ASIAN PREHISTORY}

USING LUMINESCENCE DATING

The following examples are drawn from our current program of luminescence dating in Southeast Asia to illustrate the range of fundamental questions in archaeology and paleoanthropology to which luminescence dating can be applied. Solving some of the methodological problems encountered in luminescence dating of quartz and feldspar from Southeast Asia will also ensure that the technique can be applied to geological and archaeological deposits elsewhere in the world.

\section{Late Homo erectus in Java}

Establishing when Homo erectus disappeared from Indonesia is one of the focal points of our dating program in Java. Swisher et al. (1996) were unable to demonstrate an unequivocal association between the Homo erectus remains at Ngandong and Sambungmacan and the bovid teeth that they dated using ESR/U-series methods. To breach this impasse, we have taken a new approach to the direct dating of the human remains - one not previously undertaken on hominid fossils anywhere in the world-which we call craniosediment sequencing. This novel application of luminescence dating builds upon the previous innovative use of optical dating to determine the burial ages of sediments attached to the fossil remains of extinct giant animals in Australia (Roberts et al. 2001). In the current study, we shall date the sequence of burial sediments contained inside several of the Javanese fossil hominid crania - the "craniosediments".

Some of the Homo erectus skulls from Ngandong had at least two layers of different sediment adhering inside, indicating at least one redeposition event ( $T$. Jacob, pers. comm.). The earliest sediment layer is tightly cemented to the inside of the skull, and is probably a remnant of the deposit that filled the cranial vault soon after initial burial. We consider this claim to be generally valid because to be preserved, hominid crania must have been deposited in and filled with sediment soon after death of the individual, while the force required to scour out the innermost sediments would likely smash the crania. The addition and preservation of younger sediment layers testifies to the occurrence of more recent burial events, and results in a craniosediment microstratigraphy: the oldest sediments are attached to the inside of the skull and these are overlain by successively younger sediments, which record the subsequent history of cranial transportation and redeposition. Luminescence dating of each of these microstratigraphic units should reveal the time elapsed since initial burial of the crania, as well as their complete or partial taphonomic histories.

A minimum age for the hominid remains would be obtained by dating the river terrace sediments from which the crania were recovered, and it should be possible to infer the likely original source area(s) of the Homo erectus remains by dating the flight of river terraces along the Solo River and then comparing the terrace ages with those of initial cranial burial. Craniosediment sequencing should, therefore, furnish information on the chronology, taphonomy, and provenance of reworked specimens. If this approach yields a series of stratigraphically consistent ages, then it will also provide a much more credible and robust chronology for specimens than any derived from isolated dates, especially if cross- 
checked with the results of other dating methods, such as ESR/U-series dating of associated fossil teeth. Craniosediments seem particularly well suited to this approach, but luminescence dating of sediments hidden from sunlight inside long bones is another possibility (Roberts et al. 2001).

Our work on craniosediment sequencing of late Homo erectus finds in Java began in 2001, when we collected sediment samples from the Ngandong and Sambungmacan fossil sites in collaboration with T. Jacob (Gadjah Mada University, Yogyakarta) and F. Aziz (Geological Research and Development Centre, Bandung). We also examined the Homo erectus crania held in their care, and have collected craniosediment samples from the three Sambungmacan skulls (SM 1, SM 3, and SM 4). Given the small size of these craniosediment samples, it will be necessary to employ the latest generation of single-grain optical dating methods for sand-size grains of potassium feldspar and quartz (Duller et al. 2003; Henshilwood et al. 2002; Lamothe and Auclair 1999; Lamothe et al. 1994; Olley et al. 2004; Roberts et al. 1998). Additionally, or alternatively, it may be feasible to date individual grains of quartz using the red TL signal, although such measurements are technically challenging and far from routine (Yawata and Hashimoto 2004). If sand-size grains prove scarce, then the silt-size fraction will be separated for dating (Aitken 1998). The existing cranial specimens from Ngandong contain few remnant craniosediments, but we remain hopeful that future excavations at Ngandong will unearth additional fossil hominid skulls filled with craniosediments.

In collaboration with F. Aziz, we have also begun the systematic mapping and luminescence dating of the Solo River terrace sequence that has been the supreme source of Homo erectus fossils in Southeast Asia for more than a century. Given the long-range dating potential of the red TL signal in volcanic quartz (Fattahi and Stokes 2000), we hope to obtain reliable ages for the major climate changes, geological events, and faunal and floral successions in Indonesia over the last 1.5 million years - a period that spans the entire history of human arrival, evolution, and dispersal in Southeast Asia (Larick et al. 2001). Our initial studies of quartz from Ngandong and Sambungmacan have revealed, however, that the red TL emissions are extremely dim and that more sensitive light-detection apparatus (Stokes and Fattahi 2003; Yawata and Hashimoto 2004) is required.

\section{Homo floresiensis in Flores}

To the east of Wallace's Line-the major biogeographical divide between Asia and Australia-our research has been concentrated on the island of Flores in eastern Indonesia (Figure 1). Previous excavations in central Flores have revealed evidence of human occupation by 840,000 years ago, based on fission-track dating of zircon crystals from deposits containing stone tools (Morwood et al. 1998). In the current dating program, our interest has shifted to the cave site of Liang Bua in western Flores, where we hoped to discover evidence of early modern human occupation of the island. The project began in 2001, in collaboration with R. P. Soejono (Indonesian Centre for Archaeology, Jakarta) who had conducted excavations at Liang Bua between 1978 and 1989. This large limestone cave contains at least $11 \mathrm{~m}$ of deposit, from which we have recovered human remains, stone artifacts, ochre, and the fossils of extinct animals, such as giant tortoise and Stegodon. The most significant find made thus far is a human skeleton 
found against the east wall of the cave in September 2003. The excavated remains include a skull, mandible, pelvis, and leg bones, some of which were still articulated when discovered (Morwood et al. 2004) and with sufficient distinctive features to be designated a new hominin species-Homo floresiensis (Brown et al. 2004).

Given the likely time span of the Liang Bua sequence, we have employed a range of dating techniques to constrain the ages of the artifacts and fossils. Luminescence dating has been applied to samples spanning the complete sedimentary record, including the deposits containing the Homo floresiensis skeleton. ABOXSC ${ }^{14} \mathrm{C}$ methods have been used to date charcoal fragments associated with the skeleton, but charcoal is restricted to the upper part of the sequence. For the older deposits underlying the skeleton, in which there are other remains of Homo floresiensis, we have employed ESR/U-series dating of fossil Stegodon teeth, Useries dating of calcite crystals from speleothems, and ${ }^{40} \mathrm{Ar} /{ }^{39} \mathrm{Ar}$ dating of volcanic ash deposits.

Our initial dating attempts using the OSL emissions from sand-size quartz grains were thwarted by their weak natural intensities; the same difficulties were encountered by Bonde et al. (2001) in their optical dating study of quartz from the Santorini volcanic province in southern Europe. Nakagawa and Hashimoto (2003) also reported extremely weak OSL signals from volcanic quartz, in contrast to their strong red TL emissions. Accordingly, we turned our attention to the red TL signal in quartz, as red TL is commonly emitted by quartz of volcanic origin (Fattahi and Stokes 2003; Krbetschek et al. 1997). In contrast to the samples examined from Java, we could readily detect the red TL emissions from the Liang Bua quartz grains using our existing equipment.

Figure 2 shows some of the red TL data for samples LBS7-40 (collected $1 \mathrm{~m}$ above the level of the skeleton) and LBS7-42 (collected from the same level as the skeleton). We obtained these data from aliquots composed of about 5000 grains using a modified single-aliquot regenerative-dose procedure; equipment specifications and experimental details are given in Morwood et al. (2004). Figure $2 a$ shows conventional glow curves of red TL intensity versus temperature for sample LBS7-40. To improve the signal-to-noise ratio, we decided to measure the red TL signals by heating the samples to $260^{\circ} \mathrm{C}$ and then holding them at this temperature for $1000 \mathrm{~s}$, which minimizes the unwanted red-hot glow from incandescence. The resulting isothermal decay curves for the heat-reset TL signals of samples LBS7-40 and LBS7-42 are shown in Figures $2 c$ and $2 b$, respectively, and the regenerated dose-response curves-plots of TL intensity versus applied dose - are shown in Figures $2 e$ and $2 d$, respectively. The paleodoses obtained from these heat-reset signals give rise to TL ages of $91,000 \pm 5000$ years (LBS7-40) and 95,000 \pm 5000 years (LBS7-42). These represent maximum ages for the last sediment deposition event because the aliquots are likely composed of grains derived from a number of earlier volcanic eruptions (Yawata and Hashimoto 2004), of which not even the most recent is necessarily contemporaneous with sedimentation in the cave. Hence, red TL dating using the heat-reset signal is afflicted by the same inherited age problem as ${ }^{40} \mathrm{Ar} /{ }^{39} \mathrm{Ar}$ dating, and will return true burial ages only for volcanic sediments in primary depositional context. Unfortunately, the Homo floresiensis skeleton was not underlain or overlain by in situ volcanic deposits. 
(a)

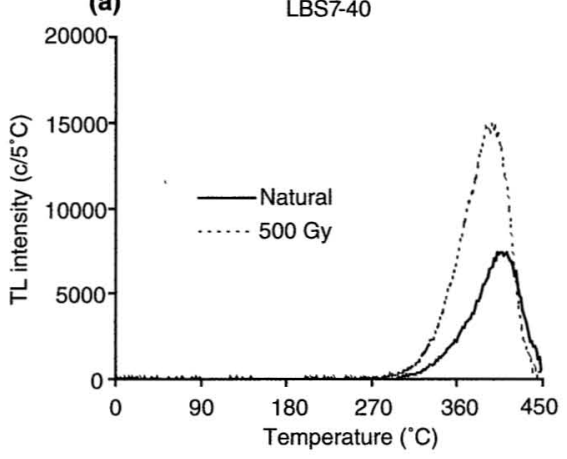

(c)

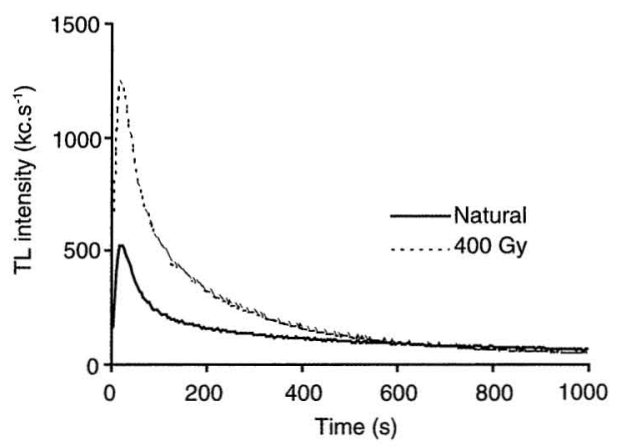

(e)

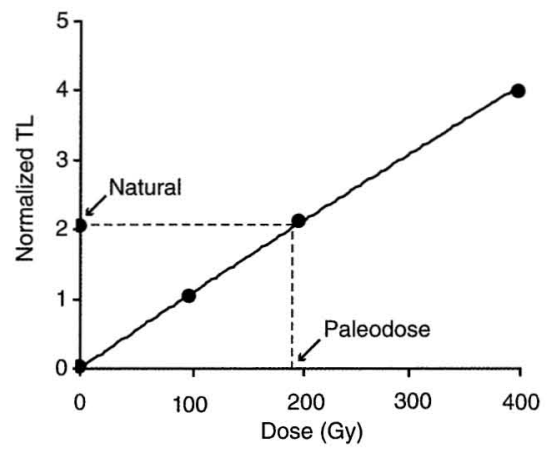

(b)

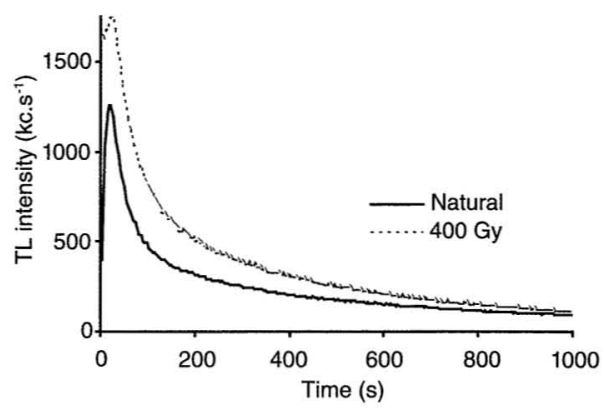

(d)

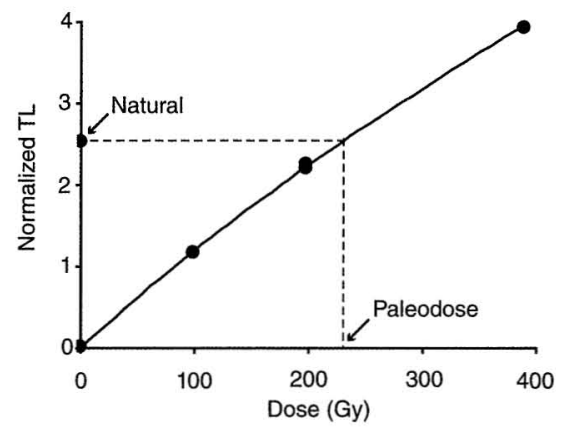

(f)

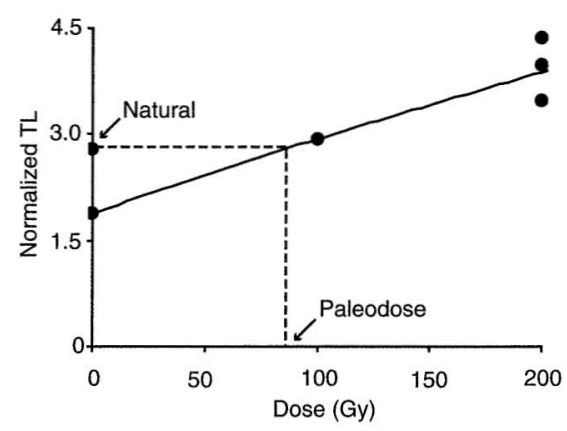

Fig. 2. Red TL dating results for quartz grains extracted from sediment samples LBS7-40 (left-hand column) and LBS7-42 (right-hand column), collected at Liang Bua, Indonesia. Glow curves of TL intensity versus temperature (measured at a heating rate of $5^{\circ} \mathrm{C} / \mathrm{s}$ ) are plotted in $a$ for an aliquot that has absorbed either the natural (field) dose or a laboratory dose of 500 Gy given after heating the natural sample to $450^{\circ} \mathrm{C}$; in both instances, the TL measurements were preceded by holding the aliquot at $300^{\circ} \mathrm{C}$ for $10 \mathrm{~s}$ and the signal arising from incandescence has been subtracted. Isothermal decay curves are shown in $b$ and $c$ for aliquots that have absorbed either the natural (field) dose or a laboratory dose of $400 \mathrm{~Gy}$, where the aliquots are heated up to $260^{\circ} \mathrm{C}$ and then held at this temperature for $1000 \mathrm{~s}$ following an initial bleach by visible $(>380 \mathrm{~nm})$ wavelengths. The regenerated dose-response curves and interpolated paleodoses for the heat-reset isothermal TL signals are shown in $d$ and $e$, and the paleodose yielded by the optically-reset isothermal TL signal in sample LBS7-42 is shown in $f$. The dose point at 200 Gy was measured twice in $d$ and $e$ and thrice in $f$, as a test of reproducibility. 
To obtain an estimate of the time elapsed since the cave sediments were last exposed to sunlight - an event that should correspond to the burial age of the skeleton-we developed a novel means of determining the paleodose for the optically-reset TL signal. Our method requires two aliquots of each sample: one to estimate the paleodose associated with the heat-reset TL signal and another to measure the total TL signal, from which the paleodose for the light-sensitive TL signal is deduced by subtraction (Morwood et al. 2004). Figure $2 f$ shows the dose-response data used to estimate the latter paleodose for sample LBS7-42. The red TL ages of $38,000 \pm 8000$ years (LBS7-40) and 35,000 \pm 4000 years (LBS7-42) for the optically-reset signals are significantly younger than those obtained from the heat-reset signals, but more accurately reflect the last time that the sediment grains were transported and redeposited. Owing to the large number of grains on each aliquot, however, and the fact that the light-sensitive TL signal requires the full visible spectrum to effect bleaching, we cannot discount the possibility that some of the grains on each aliquot had been incompletely bleached at the time of deposition. There is, therefore, potentially some inherited age component in both of these age determinations, and they should conservatively be viewed as maximum ages for deposition of the cave sediments and the Homo floresiensis skeleton buried therein.

Given this surprisingly young age for a hominin skeleton with so many primitive traits (Brown et al. 2004), we explored the potential of dating the sediments using the blue IRSL emissions from potassium feldpars. The IRSL signal is orders of magnitude more light-sensitive than the red TL signal in quartz, but it commonly suffers from anomalous fading. The effect of fading becomes magnified with time, so that the degree of age underestimation is usually less significant for younger samples. Hence, optical dating of the feldspars from samples LBS7-40 and LBS7-42 appeared to offer a means of estimating with greater accuracy the time of burial of the hominin skeleton. If the feldspars suffered from fading, then minimum ages would be obtained. The latter, taken together with the red TL ages, would effectively bracket the age of the burial event.

Figure 3 presents some of the IRSL data for samples LBS7-40 and LBS7-42. A modified single-aliquot regenerative-dose procedure was used to obtain paleodoses from aliquots composed of about 2500 grains of potassium feldspar (Morwood et al. 2004). Figures $3 a$ and $3 b$ show decay curves of IRSL intensity versus illumination time, and the regenerated dose-response curves are shown in Figures $3 c$ and $3 d$. The measured paleodoses correspond to optical ages of 14,000 \pm 2000 years (LBS7-40) and $6800 \pm 800$ years (LBS7-42). But both samples exhibited high rates of anomalous fading over laboratory timescales, plotted on a log scale in Figures $3 e$ and $3 f$, so the measured ages will be too young. Sample LBS7-40 was least afflicted by fading and returned the oldest age. As these fading rates could not be reliably extended to geological timescales, we could not correct the ages for fading using the method of Huntley and Lamothe (2001). The measured ages should, therefore, be viewed as minimum estimates of the time elapsed since the feldspar grains were last exposed to sunlight.

In combination, the oldest optical age and the youngest TL age bracket the time of deposition of the hominin-bearing sediments to between $35,000 \pm 4000$ and $14,000 \pm 2000$ years ago. This time interval is consistent with the U-series age of about 38,000 years for a flowstone that stratigraphically underlies the skel- 
(a)

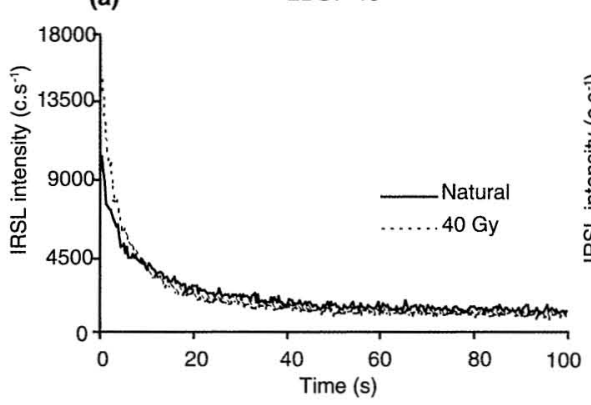

(c)

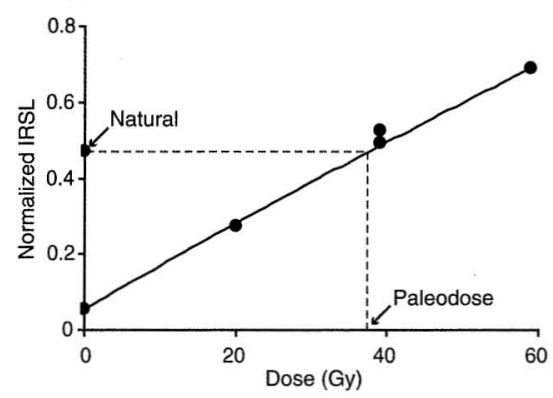

(e)

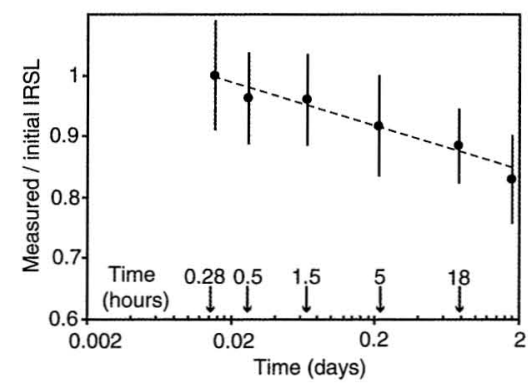

(b)

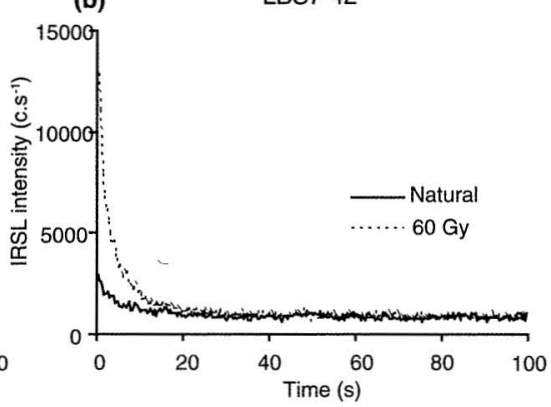

(d)

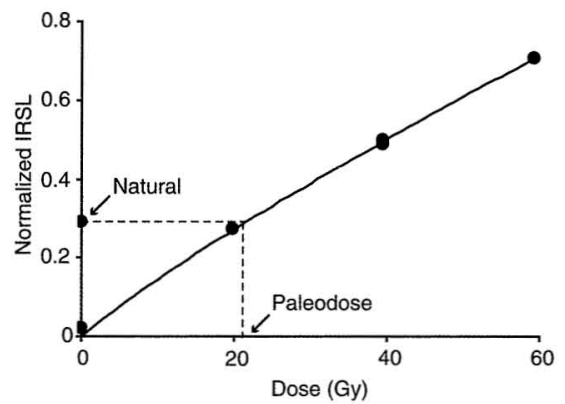

(f)

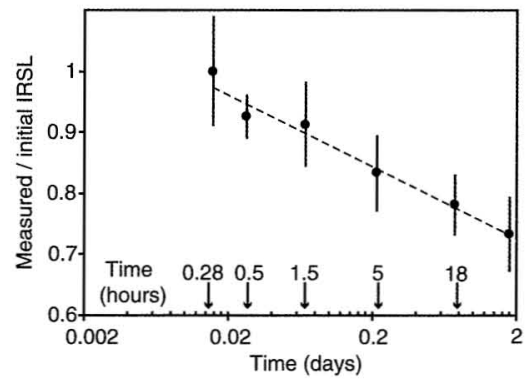

Fig. 3. Optical dating results for potassium feldspar grains extracted from sediment samples LBS7-40 (left-hand column) and LBS7-42 (right-hand column), collected at Liang Bua, Indonesia. Decay curves of IRSL intensity versus illumination time are shown in $a$ and $b$ for aliquots that have absorbed either the natural (field) dose or a laboratory dose given after an infrared bleach of the natural sample. The corresponding regenerated dose-response curves (including a repeat measurement at $40 \mathrm{~Gy}$ ) and interpolated paleodoses are shown in $c$ and $d$. Both samples exhibited significant anomalous fading of the IRSL signals over laboratory timescales, with $g$ values (Huntley and Lamothe 2001) of $10.2 \pm 3.0$ (LBS7-40) and $15.8 \pm 2.9$ (LBS7-42) percent loss per decade (where a decade is a factor of ten in time since laboratory irradiation), normalized to a measurement time of 2 days after irradiation. These fading data are plotted in $e$ and $f$, where the ordinate denotes the ratio of measured to initial IRSL intensities. Ratios are shown relative to the initial measurement at 0.28 hours, with the 2-day ratios being shifted slightly to the left for clarity of presentation. 
eton, and it encompasses the (calibrated) ages of about 18,000 years obtained by $\mathrm{ABOX}-\mathrm{SC}{ }^{14} \mathrm{C}$ dating of charcoal fragments from the same level as the skeleton (Morwood et al. 2004). These independent age estimates provide broad support for the luminescence chronology.

There are many fascinating evolutionary and archaeological implications arising from the discovery of a hitherto unknown population of tiny hominins surviving until at least 18,000 years ago in Southeast Asia, but it is beyond the scope of this paper to discuss them all here. We note that an isolated premolar of Homo floresiensis was excavated from deposits in another part of the cave, beneath the 38,000-year-old flowstone (Morwood et al. 2004). This suggests at least 20,000 years of overlap between Homo floresiensis and Homo sapiens in the region, given the skeletal evidence of modern humans dating to at least 40,000 years ago at Niah Cave on the island of Borneo (Barker et al. 2001) and at Lake Mungo in Australia (Bowler et al. 2003). Discovering and dating earlier evidence of Homo floresiensis is a key objective of our current program of research. So too is the dating of stone artifacts found in deposits older than 100,000 years at Liang Bua; at present, we cannot be certain which hominin species made these artifacts because there are no associated skeletal remains (Morwood et al. 2004).

\section{Early Homo sapiens in Malaysia}

Establishing the time of arrival of Homo sapiens in Southeast Asia is another cornerstone of our current dating program. In addition to sites in Indonesia, one of us (RGR) has begun a collaboration with Zuraina Majid (Universiti Sains Malaysia, Penang) to apply luminescence dating techniques to archaeological sites in the Lenggong Valley in Hulu Perak. This "golden valley" contains the earliest evidence of human habitation in Peninsular Malaysia, with the site of Kota Tampan (Figure 1) being perhaps the best known (Zuraina 2003). The stone tools at Kota Tampan are thought to date to about 74,000 years, based on the identification of Toba ash at the site (Zuraina 2003). Located just $3 \mathrm{~km}$ north of Kota Tampan is the site of Bukit Bunuh, where stone tools made from quartzite, quartz, chert, flint, and several types of volcanic rock have been discovered. The strong affinities in tool-making technology at the two sites led Zuraina (2003) to surmise that Bukit Bunuh had been occupied by the descendants of the Kota Tampan inhabitants, but independent age control was lacking.

Luminescence chronologies were therefore sought for Bukit Bunuh, using the blue IRSL emissions from sand-sized grains of potassium feldspar. Two sediment samples were collected for optical dating: BB2 from the cultural layer and BB1 from the overlying deposits. As at Liang Bua, paleodoses were determined using a single-aliquot regenerative-dose protocol. Figures $4 a$ and $4 b$ show representative IRSL decay curves for samples $\mathrm{BB} 1$ and $\mathrm{BB} 2$, respectively, and the corresponding regenerated dose-response curves are plotted in Figures $4 c$ and $4 d$. Both sets of data exhibit similarities to those obtained from the Liang Bua feldspars-compare Figures $4 a-d$ with Figures $3 a-d$-but a major difference is that neither of the Bukit Bunuh samples exhibited significant fading over a storage period of 86 days. Accordingly, the measured paleodoses for these two samples should yield accurate-not minimum-estimates of the time elapsed since the feldspar grains were last exposed to sunlight. 
(a)

BB1

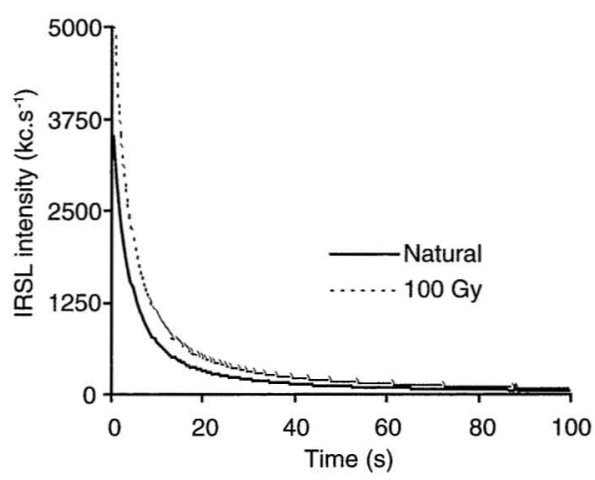

(c)

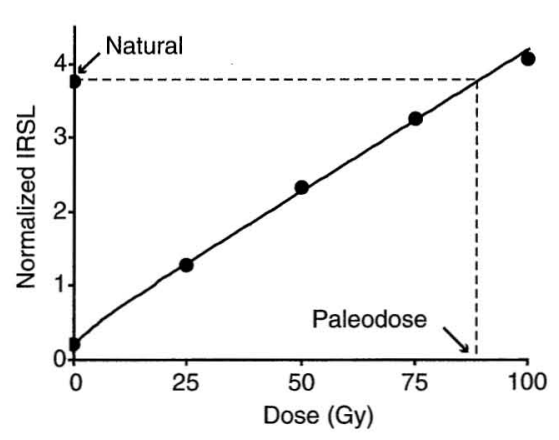

(e)

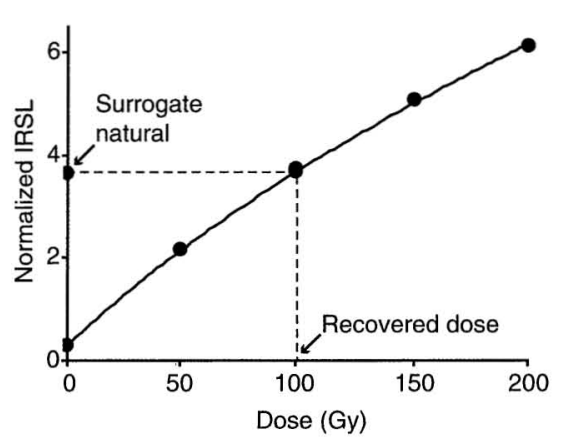

(b)

BB2

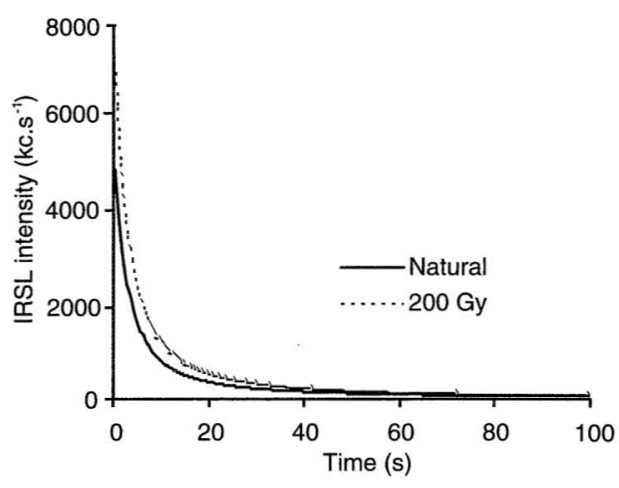

(d)

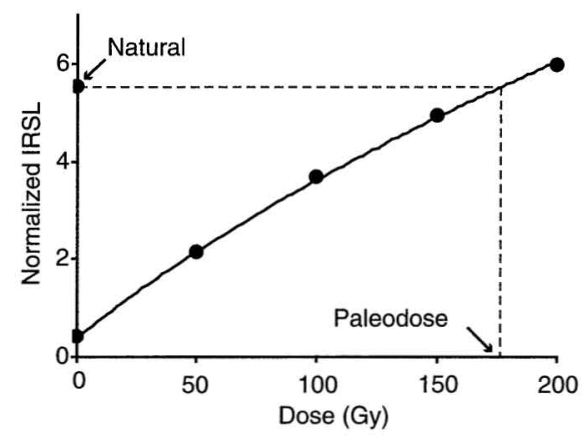

(f)

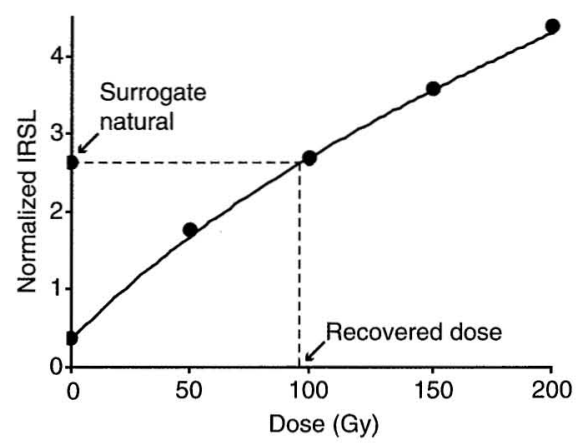

Fig. 4. Optical dating results for potassium feldspar grains extracted from sediment samples BB1 (left-hand column) and BB2 (right-hand column), collected at Bukit Bunuh, Malaysia. Decay curves of IRSL intensity versus illumination time are shown in $a$ and $b$ for aliquots that have absorbed either the natural (field) dose or a laboratory dose given after an infrared bleach of the natural sample. The corresponding regenerated dose-response curves and interpolated paleodoses are shown in $c$ and $d$, including repeat measurements at 50 Gy (BB1) and 100 Gy (BB2). Dose recovery data are shown in $e$ and $f$, where fresh aliquots of each sample were first bleached and then given a surrogate natural dose of $100 \mathrm{~Gy}$ in the laboratory. The recovered doses of $101 \pm 5 \mathrm{~Gy}$ (BB1) and $96 \pm 4$ Gy (BB2) are consistent with the given dose, thereby confirming the validity of the experimental conditions used to date these samples. 
A dose recovery test was also performed on the Bukit Bunuh samples to validate the dating procedures used, because-regardless of any age shortfall due to fading - the heat treatments applied to feldspars in the laboratory as part of the dating protocol can, in some cases, cause paleodose underestimates (Wallinga et al. 2000). In this test, fresh aliquots of sample are first bleached and then given a known laboratory dose, and the dating protocol is applied as before. Hence, only the initial bleach and irradiation in the laboratory distinguishes the natural (field) samples from their surrogate natural (laboratory) counterparts. The results of this test are shown in Figures $4 e$ and $4 f$ for samples $\mathrm{BB} 1$ and $\mathrm{BB} 2$, respectively. The recovered doses of $101 \pm 5$ Gy (BB1) and $96 \pm 4$ Gy (BB2) are both within experimental error of the known (given) dose of $100 \mathrm{~Gy}$, validating the dating protocol used for these samples. A dose recovery test was also performed on the Liang Bua samples, and similarly good results were obtained (Morwood et al. 2004), so Southeast Asian feldspars do not appear prone to some of the malign phenomena reported for feldspars from other regions of the world.

The measured paleodoses for samples BB1 and BB2 correspond to optical ages of $13,000 \pm 800$ years and $39,000 \pm 2600$ years, respectively. The existence of any fading that is too subtle to be detected by our laboratory tests would increase these ages. Zuraina (2003) discusses the archaeological context of the age of about 40,000 years for the cultural layer at Bukit Bunuh, and notes that the earliest evidence for cave occupation in Malaysia-at Niah Cave-occurs at around the same time. Given the existence of other significant archaeological sites in the Lenggong Valley, there is considerable scope for an expanded program of optical dating using the well-behaved IRSL signal from potassium feldspars. Bukit Jawa, the earliest known site in Malaysia (estimated to be around 200,000 years old), and Kota Tampan are obvious candidates, as neither site has been directly dated using modern geochronological techniques (Zuraina 2003).

\section{THE AUSTRONESIAN DISPERSAL}

The time of arrival of Austronesian speakers with pottery, ground-edge adzes, new animals, and new cultigens (e.g., rice and millet) into different regions of Southeast Asia, and the chronology of indigenous innovations in plant cultivation and animal domestication, are also major issues in world archaeology (Denham et al. 2003; Diamond 2002; Diamond and Bellwood 2003) that luminescence dating can help address. The standard scenario for Neolithic settlement of the region is that Austronesian-speaking, Mongoloid farmers dispersed initially from Taiwan into island Southeast Asia around 5000 years ago, reaching the Philippines within 500 years and most Indonesian islands within the next 500 years (Bellwood 1997). This was followed by Austronesian dispersal from the Halmahera region of northeast Indonesia into Oceania, beginning 3500 years ago, as the founder population for most Melanesians and all Polynesian and Micronesian peoples.

Dates for the dispersal of Austronesian speakers that are based on linguistic evidence have wide error margins because of uncertainties in vocabulary retention rates. High-precision dating of the appearance of pottery and other diagnostic Austronesian cultural traits at key sites is similarly problematic because of the typically small sample sizes, the vagaries of the archaeological record, and the possibility that pottery fragments and organic materials have been subject to post- 
depositional displacement, resulting in erroneously old or young ages. For example, at Uai Bobo 2 in eastern Timor, pottery fragments first appear in levels dated by ${ }^{14} \mathrm{C}$ to between 5700 and 3900 years ago (Glover 1986), while at Liang Bua in Flores we have recovered two small pottery fragments from a level dated by $\mathrm{ABOX}-\mathrm{SC}{ }^{14} \mathrm{C}$ to 6400 years ago-at least 2000 years earlier than anticipated under the conventional model of Austronesian dispersal.

Dates for pottery deposition are commonly inferred from the ${ }^{14} \mathrm{C}$ ages of associated charcoal samples, but any adverse effects due to post-depositional movement of pottery and charcoal fragments can be countered by dating the time of pottery manufacture. For example, a rice grain embedded in the matrix of a potsherd from Gua Sireh, in western Sarawak, was dated directly by accelerator mass spectrometry ${ }^{14} \mathrm{C}$ to 4500 years - an unexpectedly early date and currently the oldest for pottery (and rice) in the Indo-Malaysian region (Bellwood 1997:237). Direct dating of pottery to estimate the time of its manufacture was the original impetus for luminescence dating (Daniels et al. 1953), so deploying these techniques on the deepest pottery at selected sites in island Southeast Asia will enable the spread of pottery throughout the region to be dated with increased confidence. As in the case of Gua Sireh, some of the results obtained may not fit current models of Austronesian expansion.

At Liang Bua, we shall apply luminescence dating methods to grains of quartz and potassium feldspar embedded in the matrix of the earliest pottery to construct a solid temporal framework for the first appearance of pottery in eastern Indonesia, and the same approach could be taken at other key sites documenting Austronesian dispersal.

\section{CONCLUDING REMARKS}

Luminescence dating methods are now used routinely at archaeological and paleoanthropological sites around the world, but few applications have been made in Southeast Asia, despite the region being central to debates about human evolution, the colonization of Australia, and the spread of Austronesians. In this paper, we have outlined some of the exciting luminescence dating applications made recently in Indonesia and Malaysia, and have pointed to further avenues for inquiry that form the basis of our continuing dating program (e.g., craniosediment sequencing). In particular, we intend to focus on questions of critical importance to hominid evolution, world archaeology, and paleontology that can be addressed through luminescence dating of Indonesian archaeological and faunal (van den Bergh et al. 2001) sequences. Other dating techniques will also be employed whenever suitable materials are available, but luminescence methods will be the workhorses of the project because suitable minerals (quartz and feldspar) occur in most deposits and can yield ages for sediments exposed to light or heat during the last million years or more. Grains of quartz and feldspar may emit only a faint glimmer in the process of TL and optical dating, but in the course of our project we hope to shed much new light on Southeast Asian prehistory.

For readers interested in applying luminescence dating methods to their sites, it is important to recognize that because of the extreme light sensitivity of the optical dating signal, it is imperative that samples be collected in the field and pre- 
pared in the laboratory under dim red (quartz) or dim orange (feldspar) illumination, as is used in photographic darkrooms. A qualified dating practitioner should be consulted before sampling to obtain expert advice. General guidelines on sample collection procedures are given in the classic texts on TL and optical dating by M. J. Aitken (1985: Appendix D; 1998:60-65) and in the review articles of Lian and Huntley (2001:275) and Wallinga (2002: appendix). An important point to bear in mind is that the dose rate to the sample includes a significant contribution from gamma rays, which travel up to $30 \mathrm{~cm}$ through most sedimentary deposits. Hence, sediment samples for radioactivity analyses are required in addition to the light-safe samples collected for luminescence analyses, and the same is true for samples collected for ESR dating. The retention of in situ "witness" sections is recommended, and these should have minimum dimensions of at least $60 \mathrm{~cm}$ so that the complete gamma-ray field is preserved. At cave and rockshelter sites where the deposit is partially or completely shielded by rock, the thickness and composition of the roof must also be taken into consideration, owing to the attenuation of cosmic rays, which are a minor contributor to the dose rate.

On a final note, we wish to draw attention to a unique virtue of luminescence dating that distinguishes the technique from others used previously in Southeast Asia-namely, the potential to provide ages for reworked specimens and redeposited sediments. Because the light-sensitive signals used in TL and optical dating are set to zero each time the minerals are exposed to sufficient sunlight, the calculated age represents the time elapsed since the last bleaching event. This special feature of luminescence dating has methodological implications for the appropriate handling of newly discovered hominid remains-in particular, every effort should be made to preserve the adhering sediments, especially those within crania or long bones. Most crania held in fossil hominid collections have had any craniosediments removed during the cleaning and preparation of specimens for casting. It is important to be aware that TL and optical dating cannot be applied to craniosediments that have been exposed to light during removal, because the luminescence signals will have been fully or partially bleached. For craniosediments to be suitable for luminescence dating, it is necessary to extract them in large chunks (rather than as individual grains) and to do so under dim red or orange illumination. Estimation of the dose rate also requires special consideration, so we ask that curators of fossil hominid collections first consult with an experienced luminescence dating practitioner before removing any craniosediments. Cleaning finds for display or anatomical study is likely to destroy any possibility of dating reworked hominid (or animal) remains using luminescence methods, which rely on pockets of "dirt" as timekeepers of the distant past.

\section{ACKNOWLEDGMENTS}

We thank the University of Wollongong, the University of New England, and the Australian Research Council for funding support, and the latter organization for the award of a Senior Research Fellowship to Richard Roberts. We also thank Fachroel Aziz, Hisao Baba, Mike Barbetti, Graeme Barker, Peter Bellwood, Michael Bird, Tim Flannery, Teuku Jacob, Zuraina Majid, Jack Rink, Radien Soejono, Chris Turney, Michael Westaway, and the three anonymous reviewers for their constructive comments on an earlier version of this paper. 


\section{REFERENCES}

Aitken, M. J.

1985 Thermoluminescence Dating. London: Academic Press.

1997 Luminescence dating, in Chronometric Dating in Archaeology: 183-216, ed. R. E. Taylor and M. J. Aitken. New York: Plenum Press.

1998 An Introduction to Optical Dating: The Dating of Quaternary Sediments by the Use of Photonstimulated Luminescence. Oxford: Oxford University Press.

Aitken, M. J., M. S. Tite, And J. Reid

1964 Thermoluminescent dating of ancient ceramics. Nature 202:1032-1033.

Aitken, M. J., and H. Valladas

1992 Luminescence dating relevant to human origins. Philosophical Transactions of the Royal Society of London B 337:139-144.

Aitken, M. J., D. W. Zimmerman, and S. J. Fleming

1968 Thermoluminescent dating of ancient pottery. Nature 219:442-445.

Ambrose, S. H.

1998 Late Pleistocene human population bottlenecks, volcanic winter, and differentiation of modern humans. Journal of Human Evolution 34: 623-651.

Anderson, D. D.

1987 A Pleistocene-early Holocene rock shelter in peninsular Thailand. National Geographic Research 3: 184-198.

Antón, S. C.

2002 Evolutionary significance of cranial variation in Asian Homo erectus. American Journal of Physical Anthropology 118:301-323.

Baba, H., F. Aziz, Y. Kaifu, G. Suwa, R. T. Kono, and T. Jacob

2003 Homo erectus calvarium from the Pleistocene of Java. Science 299:1384-1388.

Barker, G., D. Badang, H. Barton, P. Beavitt, M. Bird, P. Daly, C. Doherty, D. Gilbertson, I. Glover, C. Hunt, J. Manser, S. Mclaren, V. Paz, B. Pyatt, T. Reynolds, J. Rose, G. RushwORTh, AND M. STEPHENS

2001 The Niah Cave Project: The second (2001) season of fieldwork. Sarawak Museum Journal 56 (n.s. 77): $37-119$.

Bartstra, G.-J., S. Soegondho, And A. van Der WiJK

1988 Ngandong man: Age and artifacts. Journal of Human Evolution 17:325-337.

Bellwood, P.

1997 Prehistory of the Indo-Malaysian Archipelago. Honolulu: University of Hawai'i Press.

Berger, G. W., B. J. Pillans, and A. S. Palmer

1992 Dating loess up to $800 \mathrm{ka}$ by thermoluminescence. Geolog $\gamma$ 20:403-406.

Bird, M. I., L. K. Ayliffe, L. K. Fifield, C.S.M. Turney, R. G. Cresswell, T. T. Barrows, And B. DAvid

1999 Radiocarbon dating of "old" charcoal using a wet oxidation, stepped-combustion procedure. Radiocarbon 41:127-140.

Bird, M. I., C.S.M. Turney, L. K. Fifield, R. Jones, L. K. Ayliffe, A. Palmer, R. Cresswell, AND S. ROBERTSON

2002 Radiocarbon analysis of the early archaeological site of Nauwalabila I, Arnhem Land, Australia: Implications for sample suitability and stratigraphic integrity. Quaternary Science Reviews $21: 1061-1075$.

Bonde, A., A. Murray, and W. L. Friedrich

2001 Santorini: Luminescence dating of a volcanic province using quartz? Quaternary Science Reviews 20:789-793.

Bøtter-Jensen, L., S.W.S. McKeever, and A. G. Wintle

2003 Optically Stimulated Luminescence Dosimetry. Amsterdam: Elsevier Science.

Bowler, J. M., H. Johnston, J. M. Olley, J. R. Prescott, R. G. Roberts, W. Shawcross, and N. A. SPOONER

2003 New ages for human occupation and climatic change at Lake Mungo, Australia. Nature $421: 837-840$. 
BräUER, G., AND F. H. SMITH, EDS.

1992 Continuity or Replacement: Controversies in Homo sapiens Evolution. Rotterdam: Balkema.

Brooks, A. S., D. M. Helgren, J. S. Cramer, A. Franklin, W. Hornyak, J. M. Keating, R. G. Klein, W. J. Rink, H. Schwarcz, J. N. Leith Smith, K. Stewart, N. E. Todd, J. Verniers, and J. E. YELLEN

1995 Dating and context of three Middle Stone Age sites with bone points in the Upper Semliki Valley, Zaire. Science 268:548-553.

Brown, P., T. Sutikna, M. J. Morwood, R. P. Soejono, Jatmiko, E. Wahyu Saptomo, and Rokus Awe Due

2004 A new small-bodied hominin from the Late Pleistocene of Flores, Indonesia. Nature $431: 1055-1061$.

Clark, J. D., Y. Beyene, G. WoldeGabriel, W. K. Hart, P. R. Renne, H. Gilbert, A. Defleur,

G. Suwa, S. Katoh, K. R. Ludwig, J.-R. Boisserie, B. Asfaw, and T. D. White

2003 Stratigraphic, chronological and behavioural contexts of Pleistocene Homo sapiens from Middle Awash, Ethiopia. Nature 423:747-752.

Daniels, F., C. A. Boyd, And D. F. Saunders

1953 Thermoluminescence as a research tool. Science $117: 343-349$.

Denham, T. P., S. G. Haberle, C. Lentfer, R. Fullagar, J. Field, M. Therin, N. Porch, and B.

WINSBOROUGH

2003 Origins of agriculture at Kuk Swamp in the Highlands of New Guinea. Science 301:189193.

DE Vos, J., AND P. SONDAAR

1994 Dating hominid sites in Indonesia. Science 266:1726-1727.

DIAMOND, J.

2002 Evolution, consequences and future of plant and animal domestication. Nature 418:700707.

DiAmond, J., AND P. Bellwood

2003 Farmers and their languages: The first expansions. Science 300:597-603.

Duller, G.A.T., L. Bøtter-Jensen, and A. S. Murray

2003 Combining infrared- and green-laser stimulation sources in single-grain luminescence measurements of feldspar and quartz. Radiation Measurements 37:543-550.

FALGuÈres, C.

2003 ESR dating and the human evolution: Contribution to the chronology of the earliest humans in Europe. Quaternary Science Reviews 22:1345-1351.

Fattahi, M., and S. STOKES

2000 Extending the time range of luminescence dating using red TL (RTL) from volcanic quartz. Radiation Measurements $32: 479-485$.

2003 Dating volcanic and related sediments by luminescence methods: A review. Earth-Science Reviews 62:229-264.

Feathers, J. K.

1997 The application of luminescence dating in American archaeology. Journal of Archaeological Method and Theory $4: 1-66$.

2003 Use of luminescence dating in archaeology. Measurement Science and Technology 14:14931509.

Feathers, J. K., AND D. A. Bush

2000 Luminescence dating of Middle Stone Age deposits at Die Kelders. Journal of Human Evolution 38:91-119.

Fleming, S. J.

1970 Thermoluminescent dating: Refinement of the quartz inclusion method. Archaeometry 12 : 133-145.

Franklin, A. D., J. R. Prescott, and G. B. Robertson

2000 Comparison of blue and red TL from quartz. Radiation Measurements 32:633-639.

GibBons, A.

1996 Homo erectus in Java: A 250,000-year anachronism. Science 274:1841-1842. 
GLOVer, I.

1986 Archaeology in Eastern Timor, 1966-67. Terra Australis 11. Canberra: Department of Prehistory, Research School of Pacific Studies, Australian National University.

Göksu, H. Y., J. H. Fremlin, H. T. Irwin, and R. Fryxell

1974 Age determination of burned flint by a thermoluminescent method. Science 183:651654.

Granger, D. E., AND P. F. Muzikar

2001 Dating sediment burial with in situ-produced cosmogenic nuclides: Theory, techniques, and limitations. Earth and Planetary Science Letters 188:269-281.

GRÜN, R., AND A. ThORNE

1997 Dating the Ngandong humans. Science 276:1575.

Hashimoto, T., K. Yokosaka, and H. Нabuki

1987 Emission properties of thermoluminescence from natural quartz: Blue and red TL response to absorbed dose. Nuclear Tracks and Radiation Measurements 13:57-66.

Henshilwood, C. S., F. d'Errico, R. Yates, Z. Jacobs, C. Tribolo, G.A.T. Duller, N. MerCier, J. C. Sealy, H. Valladas, I. Watts, and A. G. Wintle

2002 Emergence of modern human behavior: Middle Stone Age engravings from South Africa. Science 295: 1278-1280.

Holdaway, R. N., R. G. Roberts, N. R. Beavan-Athfield, J. M. Olley, and T. H. Worthy 2002 Optical dating of quartz sediments and accelerator mass spectrometry ${ }^{14} \mathrm{C}$ dating of bone gelatin and moa eggshell: A comparison of age estimates for non-archaeological deposits in New Zealand. Journal of the Royal Society of New Zealand 32:463-505.

Huntley, D. J., D. I. Godfrey-Smith, and M.L.W. Thewalt

1985 Optical dating of sediments. Nature 313:105-107.

Huntley, D. J., J. T. Hutton, and J. R. Prescott

1993a The stranded beach-dune sequence of south-east South Australia: A test of thermoluminescence dating, 0-800 ka. Quaternary Science Reviews 12:1-20.

$1993 b$ Optical dating using inclusions within quartz grains. Geology 21:1087-1090.

Huntley, D. J., and M. LAmothe

2001 Ubiquity of anomalous fading in $\mathrm{K}$-feldspars and the measurement and correction for it in optical dating. Canadian Journal of Earth Sciences 38:1093-1106.

HÜTt, G., I. JAEK, AND J. TCHONKA

1988 Optical dating: K-feldspars optical response stimulation spectra. Quaternary Science Reviews $7: 381-385$.

ICHIKAWA, Y.

1965 Dating of ancient ceramics by thermoluminescence. Bulletin of the Institute of Chemical Research, Kyoto University 43:1-6.

Jacob, T., R. P. Soejono, L. G. Freeman, and F. H. Brown

1978 Stone tools from mid-Pleistocene sediments in Java. Science 202:885-887.

Krbetschek, M. R., U. Rieser, L. Zöller, and J. Heinicke

1994 Radioactive disequilibria in palaeodosimetric dating of sediments. Radiation Measurements $23: 485-489$.

Krbetschek, M. R., J. Götze, A. Dietrich, and T. Trautmann

1997 Spectral information from minerals relevant for luminescence dating. Radiation Measurements 27:695-748.

Lamothe, M., and M. Auclair

1999 A solution to anomalous fading and age shortfalls in optical dating of feldspar minerals. Earth and Planetary Science Letters 171:319-323.

Lamothe, M., M. Auclair, C. Hamzaoui, and S. Huot

2003 Towards a prediction of long-term anomalous fading of feldspar IRSL. Radiation Measurements 37:493-498.

Lamothe, M., S. Balescu, and M. Auclair

1994 Natural IRSL intensities and apparent luminescence ages of single feldspar grains extracted from partially bleached sediments. Radiation Measurements 23:555-561. 
LANG, A., AND G. A. Wagner

1996 Infrared stimulated luminescence dating of archaeosediments. Archaeometry 38:129-141.

Larick, R., R. L. Ciochon, Y. Zaim, Sudijono, Suminto, Y. Rizal, F. Aziz, M. Reagan, and M. HEIZLER

2001 Early Pleistocene ${ }^{40} \mathrm{Ar} /{ }^{39} \mathrm{Ar}$ ages for Bapang Formation hominins, Central Jawa, Indonesia. Proceedings of the National Academy of Sciences of the USA 98:4866-4871.

Lian, O. B., and D. J. Huntley

1999 Optical dating studies of postglacial aeolian deposits from the south-central interior of British Columbia, Canada. Quaternary Science Reviews 18:1453-1466.

2001 Luminescence dating, in Tracking Environmental Change Using Lake Sediments. Volume 1: Basin Analysis, Coring, and Chronological Techniques: 261-282, ed. W. M. Last and J. P. Smol. Dordrecht: Kluwer Academic Publishers.

Lian, O. B., And P. A. Shane

2000 Optical dating of paleosols bracketing the widespread Rotoehu tephra, North Island, New Zealand. Quaternary Science Reviews 19:1649-1662.

Mazess, R. B., And D. W. Zimmerman

1966 Pottery dating from thermoluminescence. Science 152:347-348.

MEJDAHL, V.

1969 Thermoluminescence dating of ancient Danish ceramics. Archaeometry 11:99-104.

Mercier, N., H. Valladas, and G. Valladas

1995 Flint thermoluminescence dates from the CFR laboratory at Gif: Contributions to the study of the chronology of the Middle Palaeolithic. Quaternary Science Reviews 14:351364.

Mercier, N., H. Valladas, G. Valladas, J.-L. Reyss, A. Jelinek, L. Meignen, and J.-L. Joron 1995 TL dates of burnt flints from Jelinek's excavations at Tabun and their implications. Journal of Archaeological Science 22 :495-509.

Miallier, D., J. Faïn, M. Montret, Th. Pilleyre, S. Sanzelle, and S. Soumana

1991 Properties of the red TL peak of quartz relevant to thermoluminescence dating. Nuclear Tracks and Radiation Measurements 18:89-94.

Morwood, M. J., P. B. O’Sullivan., F. Aziz, and A. Raza

1998 Fission-track ages of stone tools and fossils on the east Indonesian island of Flores. Nature 392: 173-176.

Morwood, M. J., R. P. Soejono, R. G. Roberts, T. Sutikna, C.S.M. Turney, K. E. Westaway, W. J. Rink, J.-X. Zhao, G. D. van den Bergh, Rokus Awe Due, D. R. Hobbs, M. W. Moore, M. I. BIRD, AND L. K. FIFIELD

2004 Archaeology and age of a new hominin from Flores in eastern Indonesia. Nature 431: 1087-1091.

Murray, A. S., And J. M. Olley

2002 Precision and accuracy in the optically stimulated luminescence dating of sedimentary quartz: A status review. Geochronometria $21: 1-16$.

Murray, A. S., and A. G. Wintle

2000 Luminescence dating of quartz using an improved single-aliquot regenerative-dose protocol. Radiation Measurements 32:57-73.

Nakagawa, T., and T. Hashimoto

2003 Sensitivity change of OSL and RTL signal from natural RTL quartz with annealing treatment. Radiation Measurements 37:397-400.

O’Connell, J. F., and J. Allen

2004 Dating the colonization of Sahul (Pleistocene Australia-New Guinea): A review of recent research. Journal of Archaeological Science 31:835-853.

Olley, J. M., G. G. Caitcheon, and R. G. Roberts

1999 The origin of dose distributions in fluvial sediments, and the prospect of dating single grains from fluvial deposits using optically stimulated luminescence. Radiation Measurements $30: 207-217$. 
Olley, J. M., T. Pietsch, and R. G. Roberts

2004 Optical dating of Holocene sediments from a variety of geomorphic settings using single grains of quartz. Geomorphology 60:337-358.

Olley, J. M., R. G. Roberts, and A. S. Murray

1997 Disequilibria in the uranium decay series in sedimentary deposits at Allen's Cave, Nullarbor Plain, Australia: Implications for dose rate determinations. Radiation Measurements $27: 433-443$.

OPPENHEIMER, C.

2002 Limited global change due to the largest known Quaternary eruption, Toba $\sim 74$ kyr BP? Quaternary Science Reviews $21: 1593-1609$.

Partridge, T. C., D. E. Granger, M. W. Caffee, and R. J. Clarke

2003 Lower Pliocene hominid remains from Sterkfontein. Science 300:607-612.

PAwlik, A. F.

2001 Is there an Early Palaeolithic in the Philippines? New approaches for lithic analysis at the Archaeological Studies Program of the University of the Philippines, in Australasian Connections and New Directions: Proceedings of the 7th Australasian Archaeometry Conference: 255270, ed. M. Jones and P. Sheppard. Research in Anthropology and Linguistics 5. Auckland: Department of Anthropology, University of Auckland.

Prescott, J. R., G. B. Robertson, and F. M. Williams

2001 Luminescence ages beyond $500 \mathrm{ka}$ : Can they be believed? in Australasian Connections and New Directions: Proceedings of the 7th Australasian Archaeometry Conference: 271-284, ed. M. Jones and P. Sheppard. Research in Anthropology and Linguistics 5. Auckland: Department of Anthropology, University of Auckland.

Ralph, E. K., AND M. C. HAN

1966 Dating of pottery by thermoluminescence. Nature 210:245-247.

ReEs-Jones, J., AND M. S. Tite

1997 Optical dating results for British archaeological sediments. Archaeometry 39:177-187.

RINK, W. J.

1997 Electron spin resonance (ESR) dating and ESR applications in Quaternary science and archaeometry. Radiation Measurements 27:975-1025.

Roberts, R. G.

1997 Luminescence dating in archaeology: From origins to optical. Radiation Measurements $27: 819-892$.

Roberts, R., M. Bird, J. Olley, R. Galbraith, E. Lawson, G. Laslett, H. Yoshida, R. Jones, R. Fullagar, G. Jacobsen, and Q. Hua

1998 Optical and radiocarbon dating at Jinmium rock shelter in northern Australia. Nature 393: 358-362.

Roberts, R. G., T. F. Flannery, L. K. Ayliffe, H. Yoshida, J. M. Olley, G. J. Prideaux, G. M. Laslett, A. Baynes, M. A. Smith, R. Jones, And B. L. Smith

2001 New ages for the last Australian megafauna: Continent-wide extinction about 46,000 years ago. Science 292:1888-1892.

Roberts, R. G., AND R. JONES

2001 Chronologies of carbon and of silica: Evidence concerning the dating of the earliest human presence in northern Australia, in Humanity from African Naissance to Coming Millennia: Colloquia in Human Biology and Palaeoanthropology: 239-248, ed. P. V. Tobias, M. A. Raath, J. Moggi-Cecchi, and G. A. Doyle. Firenze: Firenze University Press; and Johannesburg: Witwatersrand University Press.

Roberts, R. G., R. Jones, And M. A. Smith

1990 Thermoluminescence dating of a 50,000-year-old human occupation site in northern Australia. Nature 345:153-156.

Roberts, R. G., R. Jones, N. A. Spooner, M. J. Head, A. S. Murray, and M. A. Smith

1994 The human colonisation of Australia: Optical dates of 53,000 and 60,000 years bracket human arrival at Deaf Adder Gorge, Northern Territory. Quaternary Science Reviews $13: 575-583$. 
Roberts, R., G. Walsh, A. Murray, J. Olley, R. Jones, M. Morwood, C. Tuniz, E. Lawson, M. MacPhaIL, D. Bowdery, and I. NaUmanN

1997 Luminescence dating of rock art and past environments using mud-wasp nests in northern Australia. Nature 387:696-699.

Sanderson, D.C.W., P. Bishop, M. T. Stark, and J. Q. Spencer

2003 Luminescence dating of anthropogenically reset canal sediments from Angkor Borei, Mekong Delta, Cambodia. Quaternary Science Reviews 22:1111-1121.

SARTONO, S.

1980 Homo erectus ngandongensis: The possible maker of the "Sangiran flakes." Anthropologie $18: 121-131$.

Scholefield, R. B., and J. R. Prescott

1999 The red thermoluminescence of quartz: 3-D spectral measurements. Radiation Measurements 30:83-95.

SHIPMAN, P.

2001 The Man Who Found the Missing Link: The Extraordinary Life of Eugene Dubois. London: Weidenfeld and Nicolson.

Singhvi, A. K., Y. P. Sharma, and D. P. Agrawal

1982 Thermoluminescence dating of sand dunes in Rajasthan, India. Nature 295:313-315.

Smith, M. A., M. I. Bird, C.S.M. Turney, L. K. Fifield, G. M. Santos, P. A. Hausladen, and M. L. DI TADA

2001 New ABOX AMS $-{ }^{14} \mathrm{C}$ ages remove dating anomalies at Puritjarra rock shelter. Australian Archaeology 53:45-47.

Stokes, S., AND M. Fattahi

2003 Red emission luminescence from quartz and feldspar for dating applications: An overview. Radiation Measurements 37:383-395.

STORM, P.

2001 The evolution of humans in Australasia from an environmental perspective. Palaeogeography, Palaeoclimatology, Palaeoecology 171:363-383.

Stringer, C.

2002 Modern human origins: Progress and prospects. Philosophical Transactions of the Royal Society of London B 357:563-579.

2003 Out of Ethiopia. Nature 423:692-695.

Swisher, C. C., III, G. H. Curtis, T. Jacob, A. G. Getty, A. Suprijo, and Widiasmoro 1994 Age of the earliest known hominids in Java, Indonesia. Science 263:1118-1121.

Swisher, C. C., III, W. J. Rink, S. C. Antón, H. P. Schwarcz, G. H. Curtis, A. Suprijo, and WIDIASMORO

1996 Latest Homo erectus of Java: Potential contemporaneity with Homo sapiens in Southeast Asia. Science 274: 1870-1874.

Templeton, A. R.

2002 Out of Africa again and again. Nature 416:45-51.

Theunissen, B., J. de Vos, P. Y. Sondaar, and F. Aziz

1990 The establishment of a chronological framework for the hominid-bearing deposits of Java: A historical survey, in Establishment of a Geologic Framework for Paleoanthropology: 3954, ed. L. F. Laporte. Geological Society of America Special Paper 242. Boulder, CO: Geological Society of America.

Troja, S. O., And R. G. Roberts

2000 Luminescence dating, in Modern Analytical Methods in Art and Archaeology: 585-640, ed. E. Ciliberto and G. Spoto. New York: John Wiley.

Turney, C.S.M., M. I. Bird, L. K. Fifield, R. G. Roberts, M. Smith, C. E. Dortch, R. Grün, E. Lawson, L. K. Ayliffe, G. H. Miller, J. Dortch, and R. G. Cresswell

2001 Early human occupation at Devil's Lair, southwestern Australia 50,000 years ago. Quaternary Research 55:3-13. 
Valladas, H., J. L. Joron, G. Valladas, B. Arensburg, O. Bar-Yosef, A. Belfer-Cohen, P. Goldberg, H. Laville, L. Meignen, Y. Rak, E. Tchernov, A. M. Tillier, and B. VanderMEERSCH

1987 Thermoluminescence dates for the Neanderthal burial site at Kebara in Israel. Nature 330: 159-160.

Valladas, H., J. L. Reyss, J. L. Joron, G. Valladas, O. Bar-Yosef, and B. Vandermeersch

1988 Thermoluminescence dating of Mousterian 'Proto-Cro-Magnon' remains from Israel and the origin of modern man. Nature 331:614-616.

VAN DEN Bergh, G. D., J. DE Vos, AND P. Y. SONDAAR

2001 The Late Quaternary palaeogeography of mammal evolution in the Indonesian Archipelago. Palaeogeography, Palaeoclimatology, Palaeoecology $171: 385-408$.

van Es, H. J., D. I. Vainshtein, A. Rozendaal, J. F. Donoghue, R. J. de Meijer, and H. W. den HARTOG

2002 Thermoluminescence of $\mathrm{ZrSiO}_{4}$ (zircon): A new dating method? Nuclear Instruments and Methods in Physics Research B 191:649-652.

VISOCEKAS, R., AND A. ZINK

1999 Use of the far red TL emission band of alkali feldspars for dosimetry and dating. Quaternary Science Reviews 18:271-278.

WALLINGA, J.

2002 Optically stimulated luminescence dating of fluvial deposits: A review. Boreas 31:303322.

Wallinga, J., A. Murray, and G. Duller

2000 Underestimation of equivalent dose in single-aliquot optical dating of feldspars caused by preheating. Radiation Measurements 32:691-695.

Waters, M. R., S. L. Forman, AND J. M. Pierson

1997 Diring Yuriakh: A Lower Paleolithic site in central Siberia. Science 275 : 1281-1284.

WESTAWAY, M. C.

2002 Preliminary observations on the taphonomic processes at Ngandong and some implications for a late Homo erectus survivor model, in Barriers, Borders, Boundaries: Proceedings of the 2001 Australian Archaeological Association Annual Conference: 189-193, ed. S. Ulm, J. Reid, C. Westcott, A. Ross, I. Lilley, L. Kirkwood, and J. Prangnell. Tempus 7. St. Lucia, Queensland: Anthropology Museum, University of Queensland.

WiNTLE, A. G.

1973 Anomalous fading of thermoluminescence in mineral samples. Nature 245:143-144.

1997 Luminescence dating: Laboratory procedures and protocols. Radiation Measurements 27: 769-817.

Wintle, A. G., And D. J. Huntley

1979 Thermoluminescence dating of a deep-sea sediment core. Nature 279:710-712.

1982 Thermoluminescence dating of sediments. Quaternary Science Reviews 1:31-53.

YaWATA, T., AND T. Hashimoto

2004 Identification of the volcanic quartz origins from dune sand using a single-grain RTL measurement. Quaternary Science Reviews 23:1183-1186.

Yoshida, H., R. G. Roberts, J. M. Olley, G. M. Laslett, and R. F. Galbraith

2000 Extending the age range of optical dating using single 'supergrains' of quartz. Radiation Measurements 32:439-446.

ZiMMERMAN, D. W.

1971 Thermoluminescent dating using fine grains from pottery. Archaeometry 13:29-52.

Zimmerman, D. W., and J. Huxtable

1969 Recent applications and developments in thermoluminescent dating. Archaeometry 11:105-108.

1971 Thermoluminescent dating of Upper Palaeolithic fired clay from Dolní Vĕstonice. Archaeometry 13:53-57.

Zuraina MajID

2003 Archaeology in Malaysia. Penang: Centre for Archaeological Research Malaysia, Universiti Sains Malaysia. 


\section{ABSTRACT}

Since the explorations of Alfred Russel Wallace and Eugène Dubois in the nineteenth century, Southeast Asia has been one of the world's focal points for studies of biogeography and biodiversity, human evolution and dispersal, environmental change, and the spread of culture, farming, and language. Yet despite its prominence, reliable chronologies are not available for many of the critical archaeological, evolutionary, and environmental turning points that have taken place in the region during the last 1.5 million years. In this paper, we discuss some of these chronological problems and describe how luminescence dating may help overcome them. "Luminescence dating" is a term that embraces the techniques of thermoluminescence (TL) and optical dating, which can be used to estimate the time elapsed since ubiquitous mineral grains, such as quartz and potassium feldspar, were last heated to a high temperature or were last exposed to sunlight. Luminescence methods have been successfully deployed at late Quaternary archaeological, paleoanthropological, and geological sites around the world, but not to any great extent in Southeast Asia. Here we describe the principles of TL and optical dating and some of the difficulties that are likely to arise in dating the volcanic minerals found throughout the region. We also outline several long-standing archaeological and paleoanthropological questions that are the subject of a current program of luminescence dating in Southeast Asia, and present recent dating results from Liang Bua in Indonesia and Bukit Bunuh in Malaysia. KeYwords: luminescence dating, archaeology, paleoanthropology, Quaternary, Southeast Asia, Liang Bua, Bukit Bunuh. 